\title{
Meta-bias: A practical theory of motivated thinking
}

\section{Hunter Gehlbach}

gehlbach@ucsb.edu

\section{Christine Calderon Vriesema}

christine.vriesema@ucsb.edu

\section{Gevirtz Graduate School of Education \#3113, University of California, Santa Barbara, Santa Barbara CA 93106-9490}

Keywords: bias, interpersonal interactions, motivation, person perception, self, social cognition, social perspective taking

\section{Acknowledgements}

This research was made possible in part by generous funding from the Robertson Foundation.

\begin{abstract}
For a host of reasons, training students and teachers to more accurately discern the thoughts, feelings, and motivations of others is more important than ever. One approach to improving social perspective taking entails teaching students to understand when and how bias impedes their efforts to "read" others. To facilitate this educational goal, we propose a theory of meta-biases that unifies and distills those biases that frequently derail perspective taking attempts. Specifically, we argue that, as a default, people strive to accurately read themselves and others. However, two competing motives-metabiases-often derail this default goal: a desire for cognitive efficiency and a need to protect or enhance one's sense of self. We hope the proposed theory proves to be: practical for educators trying to facilitate interpersonal understanding and relationships, stimulating for researchers interested in testing theory, and generative for anyone developing interventions to mitigate social cognitive biases and improve person perception attempts.
\end{abstract}




\section{Meta-bias: A practical theory of motivated thinking}

Solutions to the global problems today's children will face-immigration, economic inequality, and climate change - will likely require sophisticated navigation of interpersonal relationships between parties from very different backgrounds (Friedman, 2006). More locally, teachers and students must navigate cultural differences in their classrooms with increasing frequency. In the United States for instance, over $80 \%$ of teachers remain White while the increasingly diverse student body is now majority non-White for the first time (Egalite \& Kisida, 2017; National Center for Educational Statistics, 2012). Thus, the capacity to understand people from different backgrounds, who hold different values, and whose identities are shaped by distinct cultural forces is likely to be especially critical in the coming years. Because understanding others across these cultural and interpersonal differences will occur within highstakes contexts in many instances - e.g., addressing climate change - the stage is set for biases to impede people's efforts to take the perspective of one another (Gehlbach \& Brinkworth, 2012; Gehlbach, Brinkworth, \& Wang, 2012). To address these global challenges in the $21^{\text {st }}$ century, students and the educators preparing them require a strong, pragmatic understanding of how these biases can erode people's capacity to take the perspective of each other.

Yet, mitigating bias in our social perspective taking attempts remains an especially vexing educational challenge. One issue results from the sheer number of biases-they fill hundreds of pages of social psychology texts (e.g., Myers, 2015). Equally problematic is the entrenched nature of many biases. Societal norms, expectations, and messages embed biases deeply within our social cognitions (e.g., Nisbett, Peng, Choi, \& Norenzayan, 2001). Finally, because we frequently surround ourselves with like-minded individuals (Montoya, Horton, \& Kirchner, 2008), others in our social milieu may subtly reinforce many of our biases to the point where we fail to notice their existence.

So how can teachers - whose plates are overflowing with curricular obligations, administrative duties, and much more - carve out bandwidth to address the vast array of potentially entrenched biases that can derail students' social perspective taking capacities? How can students (or anyone for that matter), who are wrestling with the cognitive load of reading 
someone else's thoughts and feelings, sift through the dozens of biases that might impact an interaction while still engaging in the interaction? How can researchers predict which types of biases might arise for a given social perspective taking attempt? How can educators and researchers develop interventions to guard against bias derailing accurate person perception attempts?

In this article, we take a modest, but important, preliminary step towards tackling the problem of bias in our person perception attempts. Specifically, our goal in this article is to propose a guiding theory that distills, organizes, and integrates many of the biases that affect our person perception attempts. If we are successful at organizing and synthesizing these biases into a good, practical theory (Lewin, 1951), then:

(a) our theory should provide educators with a form of "usable knowledge" that allows them to more easily recognize and redress problematic perspective taking attempts and capitalize on teachable moments with their students,

(b) researchers should be able to generate new predictions regarding how biases will affect person perception attempts, and

(c) if, indeed, there is nothing so practical as a good theory, then our distillation of large families of biases into two "meta-biases" may also help researchers and practitioners to develop interventions, norms, or classroom practices that might improve students' capacities to read others.

\section{ORIENTING CONTEXT}

In this article, we view biased social cognitions as a key element within the social perspective taking process. To guide our understanding of social perspective taking, we apply Richard Snow's conceptualization of complex aptitudes (Corno et al., 2002; Gehlbach, 2004; Snow, 1996). Specifically, an aptitude encompasses multiple factors that can be brought to bear on a task through a commitment pathway (i.e., a person's motivation) and a performance pathway (i.e., a person's relevant abilities). Thus, we define social perspective taking as a perceiver's motivation and ability to discern the thoughts, feelings, motives, or point of view of one or more targets (Gehlbach, 2017; Gehlbach, Brinkworth, \& Wang, 2012). The social perspective taking process can unfold in a host of different ways - perceivers might directly experience a target's perspective through a role play or they might imagine it from a more 
psychologically distant third-person perspective (Gehlbach et al., 2015); they might engage in interpersonal perspective taking (trying to read a target while interacting with him or her) or might consider a target's perspective during an academic exercise such as taking the perspective of a historical figure (Gehlbach, 2011); they might use different strategies-for example stereotyping versus projection (Ames, 2004b; Epley, Keysar, Van Boven, \& Gilovich, 2004).

Regardless of the approach to taking another's perspective, we imagine three primary pathways to improving the underlying aptitude. First, perceivers might be motivated to engage in the process of taking others' perspectives more frequently or put more effort into their perspective taking attempts (Gehlbach \& Brinkworth, 2012). As multiple scholars using distinct approaches have shown, motivating perceivers to "turn on" their social perspective taking ability is associated with a host of interpersonal benefits including greater likelihood of detecting similarities with others, smoother interpersonal coordination, and healthier relationships (Davis, Conklin, Smith, \& Luce, 1996; Galinsky, Ku, \& Wang, 2005; Ickes, 1997).

Second, perceivers might improve their underlying ability, e.g., if educators taught students more effective perspective taking strategies (Gehlbach, Brinkworth, \& Wang, 2012). Again, substantial research links a variety of social perspective taking strategies with positive interpersonal outcomes ranging from greater prosocial motivations to decreased stereotyping (Batson, Early, \& Salvarani, 1997; Galinsky \& Moskowitz, 2000; Gehlbach et al., 2015).

Finally, if perceivers learned to identify and mitigate some of the biases that derail their perspective taking attempts, they might become more motivated and/or more accurate perceivers. In other words, even though their dispositional motivation or underlying ability might not change, they might perform closer to their true capacity for a given social perspective taking attempt by subtracting their biases out of the equation. One could fill an encyclopedia with studies with evidence that social cognitive biases can inhibit person-perception attempts (see Dunning, Griffin, Milojkovic, \& Ross, 1990; Gilbert \& Wilson, 2007; Ross, Greene, \& House, 1977 for a few examples). However, evidence also shows that de-biasing strategies can improve the accuracy of social judgments (Liberman, Minson, Bryan, \& Ross, 2011; Lord, Lepper, \& Preston, 1984). In this article, we focus on this third pathway to improving person perception attempts. 
Importantly, we presume that the biases that afflict the accuracy of our person perception attempts have emerged for a good reason. Lieberman (2013) notes that humans evolved an entire portion of their brains primarily to facilitate social interactions. Given this evolutionary development, it seems unlikely that people would then start making systematic mistakes in perceiving others with no ulterior objective. Thus, we take a functional view of social-cognitive biases by assuming they arise to serve particular psychological purposes - namely, to enhance cognitive efficiency and to preserve one's sense of self.

As outlined in the introduction, we motivate the need for an organizing theory of personperception biases with the idea that to equip today's youth with the capacities to navigate crosscultural interactions within a global society to solve challenging $21^{\text {st }}$ century problems, teachers and students will need to recognize and mitigate bias in their social perspective taking efforts. Accordingly, we stay focused on educators aiming to teach students about these biases. However, because social interactions remain fundamental to other domains - from work-life to home-life - the core premises of our theory may apply beyond educational contexts. Thus, learning how these meta-biases function will presumably be valuable for a much broader audience including, administrators, parents, and academics — not to mention politicians, business managers, and most everyone else in society.

Because one's self-perceptions are often intimately tied to one's perceptions of others, we anticipate that the basic tenets that we put forth should generally apply to perceiving the self as well as to perceiving others. Naturally, certain biases will often pertain more to self-perception while other biases primarily describe attempts to perceive others.

Finally, we are clearly standing on the shoulders of many giants in proposing this theory. The biases we describe are not new. Others have argued that multiple biases share common characteristics (e.g., Dunning, 1999; Kunda, 1990). However, to our knowledge, nobody has distilled the vast array of our social-cognitive biases down to only two fundamental meta-biases. Furthermore, we know of no theory that integrates these biases into a framework to help explain how we (mis)perceive others - one of our species' most important capacities for evolutionary survival (Lieberman, 2013). However, our theory should ultimately be judged less by novelty and more by utility: How well does it improve educators' ability to understand how socialcognitive biases affect their professional relationships and experiences? To what extent does the 
theory facilitate researchers' scientific predictions? How much does the theory facilitated the development of interventions to mitigate bias in person perception attempts?

\section{Meta-bias: An Organizing Theory of Person Perception}

With this context and these caveats in place, the proposed theory is straightforward. In line with Gehlbach and Brinkworth (2008), Kunda (1990), and Swann and Schroeder (1995), we posit that perceivers aspire to accurately understand others and themselves. In other words, perceivers are motivated to discern people's true thoughts, feelings, and motivations. This aim seems logically appropriate. It is hard to imagine how anyone would navigate their social relationships effectively with a default goal that entailed misreading others in some way. As Kunda concludes, "The case for accuracy-motivated reasoning appears quite strong" (1990, p. 482).

Furthermore, accurately perceiving others is associated with a host of benefits for perceivers so it would make sense that perceivers would be reinforced over time for accuracy. These beneficial outcomes range from better intellectual functioning, to greater social sensitivity, to more adept self-monitoring (Davis \& Kraus, 1997). Moreover, marriages between partners who are more accurate in reading each other tend to function better (Bissonnette, Rusbult, \& Kilpatrick, 1997). Conversely, adolescents who struggle to accurately take the perspective of others are at risk for a range of adjustment problems (Gleason, Jensen-Campbell, \& Ickes, 2009). More accurately taking one's own perspective (e.g., imagining how one will feel in the future) should enable better decision-making in the present, bolster happiness, and enhance well-being (Gilbert \& Wilson, 2007). In short, substantial evidence suggests that perceivers will default to trying to see themselves and others accurately... unless this goal is superseded.

We posit that two competing motives regularly trump perceivers' accuracy motivations, thereby derailing this default goal. First, perceivers will often sacrifice accuracy in person perception for the sake of cognitive efficiency. Others in our social worlds generate huge amounts of complex stimuli for us to comprehend. To manage the reading of facial expressions, tone of voice, gestures, posture, paraverbal cues, adherence to (or violations of) cultural conventions, and so forth across the scores of people with whom we may interact, we often take shortcuts or select from small (not necessarily representative) samples of data. In the words of Susan Fiske and Shelly Taylor, we are "cognitive misers" who do not like to think hard if we do 
not have to. Yet, other people are sufficiently complex that they almost always require us to think hard (Fiske, 1995).

Historically, much of the evidence that people strive for efficiency has emerged from cognitive psychology. Reviewing much of this work in Thinking, Fast and Slow, Kahneman (2011) summarizes this core idea with his description of "System 1" thinking, a system that processes information quickly and intuitively through the use of many cognitive shortcuts. These heuristics allow perceivers to apply general strategies to a range of specific situations, thus saving time and mental effort. For instance, the heuristic of anchoring and adjusting was originally understood as a cognitive bias that informed how people made decisions under uncertain conditions. Tversky and Kahneman (1974) illustrate this bias by showing that, rather than working hard to remember each of the African countries in the United Nations, if some reasonable number is proposed, people will use that number as an anchor and adjust their estimates from there. As understanding of this heuristic developed, later researchers found that the idea of anchoring and adjusting produced social-cognitive biases as well. Rather than thinking through all the complexities of how someone else might be thinking and feeling in a given situation, people might anchor their guess with their own thoughts and feelings from similar situations and make adjustments based upon what they knew about the target person (Epley et al., 2004).

Second, we will also sacrifice accuracy if we feel compelled to protect, heal, maintain, or enhance our sense of self (Kunda, 1990). In other words, if perceiving someone else accurately might inflict a blow to one's self-esteem or self-concept, misreading the target person may result (e.g., Simpson, Ickes, \& Blackstone, 1995). Presumably, this motive biases our self-perceptions more frequently than the efficiency motive. In other words, when engaged in self-perception we are likely to take more time and put forth the required cognitive effort, just not at the expense of our egos.

Historically, much of the evidence that this motive guides our social thinking has come from social psychologists reacting to the strong historical emphasis on cognitive psychology (Dunning, 1999; Kunda, 1990). Dunning (1999) argues that the people's perceptions of their social worlds are only tenuously yoked with reality because they engage in "motivated thinking" designed to retain a view of themselves that is flattering. Our view aligns more closely with 
Kunda (1990), who argues that while individuals are motivated to maintain and/or enhance their self-concept as they process their social worlds, they are constrained by their ability to provide sensible explanations for their conclusions. In other words, self-enhancing perceptions of the self and others are viable so long as people can ground those perceptions in reality. Other literatures - self-affirmation (e.g., Steele, 1988), certain views of cognitive dissonance theory (e.g., Aronson, 1992), etc.- - also suggest, albeit less directly, that protection of the ego is a core source of bias in perceivers' thinking.

Although we posit that most social-cognitive biases that implicate our person perception efforts can be understood as serving a positive self-perception or cognitive efficiency motive (or both), for space considerations we describe a only a sample of those biases, using two criteria. First, we try to present a cross-section of different types of biases that serve each of our two motives. For instance, while we describe self-fulfilling prophecies (Jussim \& Eccles, 1992; Rosenthal, 1991), we do not discuss behavioral confirmation (Snyder, Tanke, \& Berscheid, 1977) because these phenomena overlap substantially.

Second, we focus on those biases that distort teachers' and students' perceptions in more consequential ways in school settings. Thus, we could describe implicit egotism as a positive self-perception bias in which people show preferences for people, places, and things that resemble their names (Pelham, Carvallo, \& Jones, 2005; Pelham, Mirenberg, \& Jones, 2002). However, the educational consequences of people named Dennis or Denise disproportionately pursuing dentistry or Virginias residing in the state of Virginia are less clear than for the spotlight effect (Gilovich, Medvec, \& Savitsky, 2000). We are striving for a practical theory.

Through these descriptions and examples, we hope to illustrate a range of biases in person perception attempts that serve the underlying motives of improving our cognitive efficiency or protecting our sense of self and, in turn, affect the social dynamics of the classroom. Despite constraining the number of illustrations, the selection of our examples should allow readers to see how most other social-cognitive biases related to person-perception map onto our two underlying motives even when we do not specifically mention them. As Figure 1 illustrates, many of the biases emerge primarily as a function of one motive of the other, but some biases can serve both motives depending on the situation. 
Figure 1: Conceptualization of how a sample of person perception biases align within the meta-bias framework

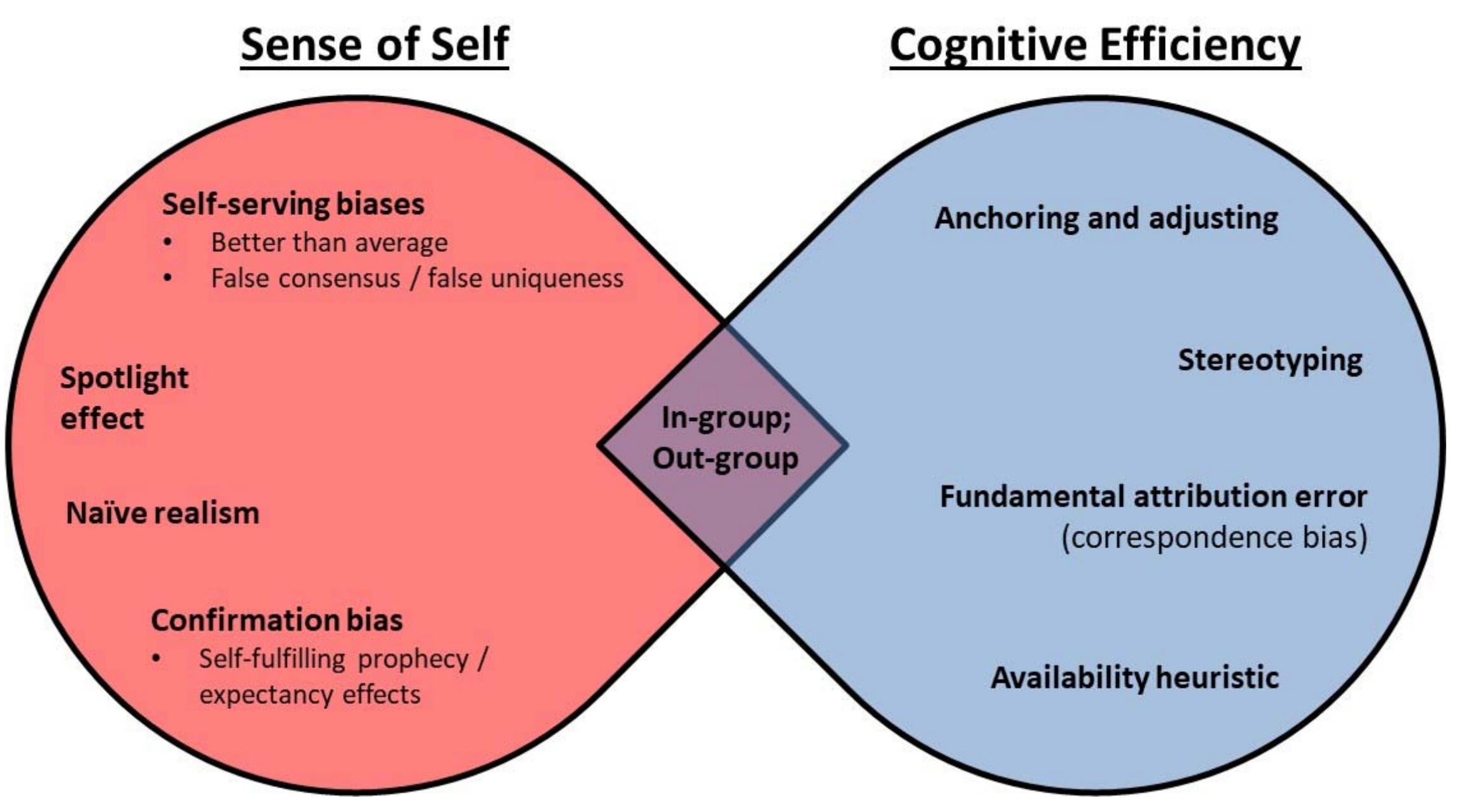




\section{COGNITIVE EFFiCienCy}

We first look at those biases that, although ostensibly distinct, all serve to reduce the time and effort that people spend thinking.

Anchoring and adjusting. Anchoring and adjusting describes a heuristic for making judgments under conditions of uncertainty. Because perceivers tend to find others complex, frequently changing, and potentially deceptive (Ekman, O'Sullivan, \& Frank, 1999), their judgments about others almost always entail uncertainty. Perceivers often initiate the process of discerning the target's thoughts or feelings by using themselves as an initial anchor-e.g., by asking, "What would I do or think or feel in that situation?" (Eyal, 2018; Tamir \& Mitchell, 2013). However, because perceivers often appreciate that they are not identical to any target, they adjust from that initial anchor to more accurately read the target person. A key characteristic of this process is that these adjustments systematically fail to go far enough (Epley \& Gilovich, 2006; Epley et al., 2004). For instance, a high school teacher may imagine that she sees her $9^{\text {th }}$ grade self in one of her students. Consequently, she may default to trying to take the student's perspective by recollecting one of her own $9^{\text {th }}$ grade experiences as an anchor and then adjusting (insufficiently) to account for ways in which she knows she and her student differ.

This strategic approach to reading others achieves efficiency, at the expense of accuracy, in two ways. First, perceivers' own thoughts, feelings, and motives are much more accessible and memorable to them than the thoughts, feelings, and motives of anyone else (Pronin, Kruger, Savtisky, \& Ross, 2001). Thus, anchoring with their own experience should save substantial cognitive effort in the first step of this process. Second, scholars find that one reason people's adjustments are chronically insufficient is because they stop adjusting once they reach a plausible conclusion (Epley \& Gilovich, 2006; Tamir \& Mitchell, 2013). In other words, they do not take the time to exhaustively search for the most accurate inference. Instead, they stop upon arriving at a good enough conclusion. Importantly, perceivers appear to engage in this perspective taking strategy primarily when they intuit some degree of similarity between themselves and the target (Ames, 2004b; Tamir \& Mitchell, 2013).

Stereotyping. When perceivers sense a lack of similarity with a person or group they are trying to understand, they often engage in a different strategy for reading others: stereotyping (Ames, 2004a). In this approach, perceivers realize that they differ from the target to the point 
where their own experience fails to provide a reasonable anchor. Thus, to read the target person, they think about what most people typically do, think, feel, etc. in a particular type of situation. Stereotypes vary in their level of nuance. For instance, one teacher might think about where most of her students stumble in learning math; another might think about where most male, nonnative English-speaking athletes who become easily frustrated end up struggling in their understanding of the quadratic formula.

Even nuanced stereotypes create efficiencies because these stereotypes allow perceivers to think in categories, schemas, or groups of people rather than processing individuals one at a time (Fiske, 1995). However, relying on stereotypic thinking frequently sacrifices accuracy when the wrong schema or prototype is applied (e.g., applying the easily-frustrated, male, nonnative English speaking athlete stereotype to a male, non-native English-speaking athlete who is not frustrated) or when the stereotype simply does not fit the individual (e.g., how most frustrated, male, non-native English-speaking athletes would feel does not apply to this particular student).

Fundamental attribution error; Correspondence bias. In committing the fundamental attribution error, perceivers overestimate the effect of dispositional factors and underestimate the impact of situational factors in explaining others' behavior (Ross, Amabile, \& Steinmetz, 1977). Often referred to as correspondence bias, the basic idea is that perceivers often conclude that targets' behavior corresponds to their disposition - an easier conclusion than seeking situational explanations for understanding why others behave as they do (Gilbert, 1995). Notably, perceivers do not typically fall into this thought pattern when passing judgment on their own behavior (Jones \& Nisbett, 1971). Moreover, this bias may be more prevalent in some cultures (e.g., among people with more individualistic backgrounds) than others (e.g., collectivist cultures; Nisbett et al., 2001). In the classroom, this attributional style may manifest itself in a host of ways ranging from classmates assuming a certain boy is a "bad kid" because of his disruptive behavior, to a teacher grading a student's essay generously because the student is generally "clever."

Regardless of whether this bias is positively or negatively valenced for a particular student, it reduces a perceiver's cognitive effort substantially. To infer that a disruptive child is "bad" or an incisive comment came from a "clever" student is a straight-forward causal sequence 
that requires little imagination on the part of the perceiver. By contrast, to imagine the multiple situational factors at home, on the way to school, and in the hallways that might partially contribute to disruptive behavior, requires much more creativity and cognitive effort. Similarly, appreciating the contributions of educated parents, social class, and other trappings of privilege takes a lot of extra thinking when most of one's brain is occupied by grading dozens of essays.

Availability heuristic. The availability heuristic describes a process in which a person conjures up instances of a certain phenomenon, notes how easily these occurrences came to mind, and then infers the prevalence of the phenomenon based on the ease of their recollections. Tversky and Kahneman (1974) illustrated and popularized this bias through examples such as asking people, "Does the letter " $\mathrm{k}$ " appear more frequently at the start of a word or as the third letter in a word?" To answer, people can search their memories for "k" words. Typically, "kayak," "kite," and "kitten" leap to mind much more readily than "take," "acknowledge," or "ink," even though more words have "k" as their third letter than as their first (Kahneman, 2011). Because of how people typically search their memories, words that start with "k" are more available than words containing " $\mathrm{k}$ " as the third letter. As a result, most people answer this question incorrectly. However, the availability heuristic plays an important role in person perception too.

From a teacher's perspective, the instances of students' disrupting class are inevitably more salient than instances of them sitting quietly, staying on task, and getting their work done. As a result, disruptions and misbehavior tend to be more available in a teacher's mind and can be recalled from memory more readily. These easily recollected - and therefore, presumably prevalent - instances may, over time, become aggregated into repeated attributions or stereotypes of particular students (Kunda \& Sinclair, 1999; Weiner, 1994).

Clearly, drawing inferences based on what comes to mind readily is a mental shortcut that can save perceivers from the hard work of thinking through uncommon events or dredging their memories for events that were not particularly salient. Thus, the availability heuristic provides another illustration of perceivers sacrificing accuracy to save themselves time and cognitive effort.

Cognitive efficiency illustration. So how might this meta-bias play out in classrooms as teachers and students attempt to perceive one another accurately? As one illustration, think 
through the multifaceted tasks embedded in the act of teaching. Teachers must simultaneously: convey ideas from a curriculum to their students, monitor students' individual understandings of that curriculum, track the timing and pacing of the lesson, adjudicate the balance of participation in the class for individual students, evaluate each student's engagement, and much more. To say that teaching puts teachers under substantial cognitive load is surely an understatement. Because social perspective taking is inhibited under conditions of cognitive load (Davis et al., 1996; Gehlbach, Brinkworth, \& Wang, 2012), it seems plausible that teachers might be particularly susceptible to becoming cognitive misers during teaching (Fiske, 1995). Any of the efficiency biases might allow teachers to manage this cognitive load. However, by relying on whatever information is most available, assuming that students' behaviors correspond with their dispositions, anchoring with their own experience, or any other cognitive efficiency bias, the risk is that teachers will make more errors in their social perspective taking attempts. These errors may inhibit teachers' abilities to understand which students are comprehending a lesson, whether the class is engaged, why particular students may endorse particular points of view, and so forth.

As another example, one of the most consistently successful classroom structures for students' learning entails the thoughtful use of cooperative groupwork (Johnson \& Johnson, 2009; Lotan, 1997). Part of the success of these structures is that students are exposed to the different points of view of their classmates and thus, learn to see issues from different perspectives. However, these structures require students to interact with classmates who come from different backgrounds than their own. In these contexts, the natural tendency to conserve cognitive effort (e.g., by stereotyping peers) may override students' motivations to understand their peers accurately. When this occurs, it will likely attenuate social and cognitive benefits of groupwork because social bonds will likely be weakened (Galinsky et al., 2005) and appreciation of alternative points of view diminished (Cacioppo \& Petty, 1982).

In either case, knowledge of our theory should have practical applications. Educators who have a basic understanding of our theory should be able to sense when they are feeling particularly overwhelmed cognitively as they are teaching. Knowing the problems that it might lead to, they can enact strategies to slow down the pace of class when this happens-e.g., instructing students to think for two minutes and jot down some notes prior to responding to a question. Likewise, if teachers detect that groupwork structures are not working as well as they 
could because students are taking cognitive shortcuts, they can address the problem through specific strategies to scaffold more rigorous thinking such as assigning students to roles like playing devil's advocate (Cohen, 1994).

Protecting, Maintaining, And Enhancing our Sense of Self

By contrast, a host of biases do not necessarily speed cognitive processing or save mental effort. However, they still undermine people's motivation to perceive others accurately - this time by trying to protect, maintain, or enhance one's sense of self.

Self-serving biases. One particularly well-researched family of these mental heuristicsself-serving biases - serves primarily to bolster perceivers' self-perceptions. In one illustrative self-serving bias, the better-than-average-effect, scholars have found that, like Lake Wobegon, where all the children are above average, people typically think of themselves as above the mean in most (reasonably socially desirable) domains (Myers, 2015). Individuals also think that most people agree with them - the false consensus effect (Ross, Greene, et al., 1977). Yet, when it comes to their talents, skills, and abilities, they believe they stand out-false uniqueness (Goethals, Messick, \& Allison, 1991). In one particularly ironic demonstration of these selfserving biases, Kruger and Dunning (1999) showed that students who do particularly badly on tests (e.g., of logic or grammar) still perceive themselves to be above average. The authors suggest that people's poor skills in the domain rob them of the metacognitive awareness to realize their low abilities. The implications of self-serving biases for educational settings abound: students who think they do not need to study as much as their peers, teachers who assume their students will enjoy Shakespeare as much as they did when they were a student, and regular disappointments that others fail to appreciate one's invaluable contributions to collaborative groupwork tasks.

Like the cognitive efficiency biases, these self-serving biases sacrifice accuracy in person perception. However, because the perceptions in these instances are typically self-perceptions (rather than perceiving others), the sacrifice is made in order to reap self-esteem benefits. Researchers (e.g., Kruger \& Dunning, 1999) know participants' perceptions are inaccurate in these studies because they contrast people's self-perceptions against a local peer group (e.g., all the other students in the class). Thus, unlike Lake Wobegon, not all participants in these studies can be above average - on average, they are (necessarily) average. 
Spotlight effect. The spotlight effect refers to perceivers' tendency to overestimate how much others notice them (Gilovich et al., 2000). Thus, this bias combines individual's self- and other-perceptions by focusing on how people think others perceive them. Through five studies, Gilovich et al. (2000) established that the bias generalizes from potentially embarrassing to potentially flattering clothing, as well as extending from appearance (e.g., t-shirts) to behaviors (e.g., verbal contributions to a discussion). Whether their college student participants wore embarrassing t-shirts (with Barry Manilow's image) or flattering ones (with their choice of Bob Marley, Jerry Seinfeld, or Martin Luther King Jr.), they overestimated how much others in a room would notice their appearance (relative to the others' actual noticing). Likewise, students overestimated the salience of their positive and negative contributions in a group discussion (relative to how much others' noticed these contributions).

Through these studies, this bias illustrates how perceivers' goal of accurate understanding competes with and is often undermined by a general need to see oneself as relevant, important, and consequential in social situations. For the sake of one's ego, it seems reasonable to trade-off some accuracy in one's self-perception to ward off the belief that nobody is paying attention. This trade-off seems clear in instances such as the flattering t-shirts. Yet, Gilovich et al. (2000) found evidence of the spotlight effect for prospectively embarrassing clothing (and negative conversational contributions) as well. One interpretation is that the spotlight effect could damage the ego in this particular instance. On the other hand, from the perspective of a longer timeframe, anticipating the embarrassment of wearing a Barry Manilow t-shirt (or saying something foolish), allows students to take appropriate preventative steps a priori-avoiding embarrassment altogether and protecting one's sense of self. This bias may hold particular relevance for teenage classrooms. In particular, this bias has implications for students speaking up in class, articulating a minority point of view, and perceiving who is contributing how much to groupwork projects.

Naive realism. Naïve realism reflects perceivers' tendency to view their own beliefs as objective while viewing others' beliefs as subjective (Robinson, Keltner, Ward, \& Ross, 1995). Robinson et al. (1995) describe this bias as an "unshakable conviction that [one is] somehow privy to an invariant, knowable, objective reality - a reality that others will also perceive faithfully, provided that they are reasonable and rational" (p. 405). When targets do not perceive 
this objective reality in the same way as a perceiver, it is because (a) they were exposed to different information - information that a perceiver generally assumes to be lesser than the information s/he is privy to, (b) they are too lazy, irrational, or unwilling to process the information properly, or (c) they are biased (Ross \& Ward, 1996). This bias might arise in educational contexts in a number of different ways - parents who "know" that their child deserved an A, for example. However, among the most worrisome instances are when students and teachers try to understand others' divergent perspectives on sensitive topics such as climate change.

This bias is particularly functional. Viewing one's own beliefs as synonymous with objective reality is critical to maintaining a grounded sense of self - it is hard to imagine how anybody could function without confidently believing that their perceptions are firmly grounded in reality. Naïve realism further reinforces one's sense of self in two ways. First, perceivers often strengthen their own belief systems by comparing their beliefs with those who hold similar values - a process that individuals typically find reaffirming (Montoya et al., 2008). Second, when perceivers do encounter those who hold divergent views, naïve realism provides a process through which they can discount the opposing perspective.

Confirmation bias. Confirmation bias occurs when perceivers subconsciously seek out or interpret information to align with their preexisting beliefs. In other words, once perceivers adopt a particular set of beliefs - a pet theory about something or someone - they heavily weight information that supports their theory, but devalue or dismiss information that contradicts their working hypothesis (Nickerson, 1998). Of particular relevance for educational settings is the work on self-fulfilling prophecies and expectancy effects (Brophy, 1983; Jussim \& Eccles, 1992; Rosenthal \& Jacobson, 1968). This subset of studies examines a form of confirmation bias and its behavioral consequences. In what is arguably the most famous study in this domain (Rosenthal \& Jacobson, 1968), teachers were told that a special predictive test identified certain students who were expected to make large leaps in their academic progress that year (in reality these students were randomly assigned). Over the course of the year, teachers then proceeded to behave in ways that helped them confirm the pet theories that were planted by the researchers. Consequently, these students ended up performing significantly better than their peers for whom no suggestion of substantial academic growth had been seeded by the experimenters. Later 
research has clarified that teacher expectancies typically result from a combination of teachers accurately reading their students' abilities and biased behaviors that tend to confirm their preexisting beliefs about students (Brophy, 1983; Jussim, Crawford, \& Rubinstein, 2015).

Confirmation bias affirms perceivers' sense of self because it confirms that their perceptions were correct all along. Although perceivers could consider alternative informationwhich might result in more accurate inferences about our social world — doing so would decrease the certainty felt in their judgments (Nickerson, 1998). Therefore, confirmation bias protects and promotes individuals' sense of self by bolstering their confidence that their beliefs are correct and removing possible sources of self-doubt.

It is particularly worth noting that confirmation bias may interact with, and amplify many of the other biases discussed here (Gilovich \& Ross, 2015). For instance, students who feel that the spotlight shines too brightly on them when called on to participate in class, will likely look for and find evidence that other students are staring. Yet, they will overlook those classmates who continue to be oblivious to their presence. A teacher's dispositional attribution about an "irresponsible" student who has missed a few homework assignments may get reinforced as the teacher disproportionately attends to further instances of missed homework but discounts those assignments that are submitted, thus helping reify the correspondence bias. When entertaining someone else's divergent perspective, confirmation bias allows perceivers to search primarily for examples that support their preexisting beliefs and thus conclude that their perspective was right all along - thereby reinforcing naïve realism.

Self-enhancement illustration. Classrooms can be delicate places with respect to people's egos. Teachers often put substantial time into lesson planning which may or may not be appreciated by students. Students frequently feel vulnerable in taking intellectual risks (e.g., getting wrong answers in front of others). As a result, it should be unsurprising that both teachers and students default motive to accurately perceive others may be derailed by selfenhancement biases. Yet, when teachers or students protect their egos through self-enhancement biases, they may be disproportionately likely to create perceptual blind-spots that diminish their efficacy in teaching and learning, respectively. When teachers (or students) believe that their lessons (or homework) are better than average, presume that students (or teachers) who do not 
appreciate this stellar work cannot not see objective reality, etc. it can strain all-important teacher-student relationships (Gehlbach, Brinkworth, \& Harris, 2012).

\section{EfFicient Self-Enhancement}

Some biases may undermine the accuracy with which we read other people in the service of both cognitive efficiency and self-protection.

In-group, out-group. Perhaps the best example of a bias that serves both motives simultaneously is in-group/out-group bias. Building upon the tendency to stereotype othersparticularly those who are dissimilar - perceivers then frequently categorize people as belonging to their in-group or an out-group. In the same way that individuals have multiple identities, people belong to many different in-groups (with distinct corresponding out-groups). Once an ingroup distinction has been made, perceivers tend to favor the in-group over the out-group, often to the point of active discrimination against or derogation of the out-group (Devine, 1995; Hewstone, Rubin, \& Willis, 2002). Especially in middle and high schools, salient groups of students that reify into cliques may be particularly problematic.

This bias serves the ulterior motive of cognitive efficiency in much the same way as stereotyping. Rather than having to consider others individually, targets can be easily sorted into an in-group or an out-group; furthermore, a default notion of how to behave towards members of these groups (e.g., approach or avoid them) is also immediately created, saving further cognitive effort. Simultaneously, because the in-group is viewed more favorably than the out-group, the perceiver's self-esteem receives a boost.

\section{CONNECTIONS TO RELEVANT LITERATURES}

By distilling numerous biases down to the two meta-biases of efficiency and selfenhancement as the primary obstacles in accurately perceiving others, we reveal overlaps with several related literatures. For instance, our theory connects to work on emotion regulation and empathy. Gross (1998) describes a progression of different emotion regulation strategies, including actively modifying situations or cognitively reframing the meaning of a situation. Our theory highlights that perceiving others remains a bias-ridden process. Knowing that perceivers' accuracy motives may often be derailed could help perceivers modify or reframe situations so as to enhance their emotion regulation. For instance, imagine a teacher who is growing frustrated 
with a high-potential, under-performing student who claims to be so much better than his peers that he does not need to study. The teacher might remember that most of us protect our egos and that thinking we are above average is one (biased) means to that end. As a result, the teacher might then help the student modify his perception of the situation by discussing how much highly performing students study on average (rather than the school-wide norm). By helping the student reframe the implicit comparison, the teacher might help shift the student's sense of whether he really is "better-than-average," and perhaps even change his study habits.

Likewise, recent (e.g., Zaki, 2014) and older (e.g., Simpson et al., 1995) scholarship describes how people are motivated to feel (or avoid) empathy, even if such motivations potentially lead to inaccurate perceptions. Simpson et al. (1995) provide a prototypic example in which dating couples who were less secure in their relationships were less accurate in reading their partners when they were threatened by the specter of their partner meeting an attractive member of the opposite sex. Many classrooms hold "no excuses" policies that may inadvertently lead teachers to generate similarly inaccurate understandings of their students. Such policies may allow teachers who are daunted by the cognitive load of listening to, empathizing with, and adjudicating students' problems to simply avoid these conversations - even if they fail to learn about deaths in the family, financial problems, teenage heartbreak, health issues, and the other challenges many students face. Thus, our two meta-biases may shed light on how and why people are motivated to feel (or avoid) empathy.

Finally, we see an important complementarity with scholarship regarding how we differentially perceive bias in ourselves versus others (Pronin, Gilovich, \& Ross, 2004). Specifically, Pronin et al. (2004) argue that perceivers think of themselves as having finely calibrated bias-detectors that can see other people's motivated thinking in sharp relief. However, perceivers tend to have a substantial blind-spot when it comes to the possibility that they, too, might be biased in their perceptions of the world. This asymmetry in bias fits squarely within the motive to misperceive social worlds in the service of protecting or enhancing one's sense of self (i.e., it would not reflect well on perceivers if they admitted they were as biased as everyone else). Importantly, we also see this asymmetry as playing a critical role in many of the interpersonal conflicts that arise in educational settings - for example, some teachers may think that students are too biased to understand the realities of the larger classroom that teachers can 
see clearly from the vantage point of their role. Conversely, some students may become frustrated that their teachers show preferential bias towards certain student subgroups over others - a bias that they see clearly, though (they perceive that) their teachers cannot.

\section{LIMITATIONS AND FUTURE DIRECTIONS}

In entertaining some of the potential limitations of our theory, we embrace Lord, Lepper, and Preston's (1984) debiasing strategy of "considering the opposite" (an antidote to confirmation bias). Specifically, we address opposing possibilities with respect to the two metabiases we propose as core motives and the specific biases we address.

First, some may argue that we selected the wrong core motives or have the wrong number. For example, Gawronski (2012) proposed cognitive consistency as a core motive. Although it is a motive that undoubtedly drives many of our actions, if one further questions why we strive for cognitive consistency, we think a crucial reason is the need to perceive ourselves as stable, competent, and morally good (Aronson, 1992). Thus, we view cognitive consistency as a manifestation of our motive to protect, maintain, and enhance our sense of self.

Alternatively, in focusing on self-perceptions, Swann and colleagues (Swann, 1997; Swann \& Schroeder, 1995; Swann, Stein-Seroussi, \& Giesler, 1992) argue that self-verification is a primary motive. In other words, we strive to verify that others perceive us in the same way that we perceive ourselves. This desire for self-verification may occur even when others' perceptions are negative (Swann, 1997). Although some could take this as an important exception to our self-enhancement motive, we would note that self-verification is essentially the same idea as our default goal of perceiving people accurately. The main difference is that Swann and colleagues restrict their focus to self-perceptions; our theory encompasses self- and interpersonal-perception. Thus, having people strive to accurately understand themselves (or how others perceive them) is perfectly congruent with our theory. The motive for accurate person perception will, at times, override the motive for self-enhancement; at times, the opposite will also occur.

As another alternative, perhaps it makes more sense to view people as intuitive scientists (Ross, 1981). In this case, our misperceptions of others and/or ourselves are not motivated per se. Rather, they are explained by common mistakes that people make in the informal data 
collection and analysis processes that they employ to make sense of their social worlds (e.g., people's efforts to generalize inferences from a sample to a larger population or to assess covariation are typically flawed). Kunda (1990) and Dunning (1999) provide numerous examples of studies that can be explained by understanding perceivers as motivated reasoners but not by understanding them as intuitive scientists. For instance, many of Dunning's studies hold constant the background information that participants learn but vary their motivations to produce distinct biases in their reasoning (see Dunning, 1999 for a review). Thus, we think this alternative explanation is also unlikely.

Second, even if we have correctly identified the two meta-biases that can derail our goal of accurately perceiving others, specific biases may not align with our two core motives. For instance, we described the better-than-average effect as a clear illustration of protecting or enhancing the ego. However, Kruger (1999) also describes a "below-average" effect in which he asks students about domains that are generally perceived to be hard-e.g., chess, juggling, and computer programming - and finds that they systematically rate themselves below the average of their peers. At first, this finding hardly seems consistent with a motive to enhance one's ego. However, Kruger suggests that "How do I compare with my peers?" is a particularly complicated question (requiring an evaluation of self, an estimate of the average ability of the peer group, and then a comparison). Kruger hypothesizes that respondents may replace that challenging question by instead answering an easier proxy like "How good am I in this domain?" Thus, an argument could be made for the above and below average effects to serve the cognitive efficiency motive. We also speculate that many of the challenging domains that Kruger asks about are likely to be less central to students' identities than the domains in which he finds better-than-average effects. In other words, college students who are below average in their athletic ability would generally worry about it more than those who are below average in their juggling ability. Thus, arguments can be made that this particular bias still comports with our basic tenets reasonably well. Nevertheless, if there are other person perception biases that do not fit our tenets, the viability of our theory would be weakened.

Third, there may be biases that fit our framework for some subgroups of people but not others. Hostile attribution bias provides a reasonable example (Crick \& Dodge, 1996). This bias refers to instances in which perceivers view others' ambiguous behavior as motivated by 
aggression rather than considering a broader range of reasons for their actions. For some, this bias may spark an aggressive reaction that leads to costly conflict or fights. In this case, hostile attribution bias does not seem particularly self-protective or self-enhancing. However, in some situations hostile attribution bias can also serve a crucial self-protection motive by encouraging perceivers to avoid particular individuals or groups in the moment.

In addition, there may be important cultural differences in how biases manifest among perceivers. For instance, Nisbett et al. (2001) argue that Asians fall victim to the fundamental attribution error less frequently than those from western European backgrounds. To the extent that this bias does emerge in Eastern cultures, it may serve different core motives in perceiving others. We view the generalizability of our theory across cultures as a particularly important and intriguing area for future research.

Finally, we appreciate that in some instances biases may serve one underlying motive while undermining the other. For instance, we presented the availability heuristic as a bias that primarily facilitates our need for cognitive efficiency. However, in one study, both husbands and wives rated themselves as being responsible for more than half of their marital conflict because their own actions were more available than those of their partners (Kahneman, 2011). Despite the efficiency of this conclusion (i.e., both parties do the quick, easy recollecting of their own behaviors rather than the harder, longer thinking involved in recalling their spouse's behaviorswhich are less available), it provides little obvious benefit for one's ego. For now, we make no claims as to when and where one meta-bias might override the other. Nor do we make claims about the exact amount of overlap that might exist between these motives-Figure 1 is not necessarily drawn to scale. After more empirical work takes place, such claims may be possible. This set of questions provides another intriguing area for future research.

\section{IMPLICATIONS OF THE THEORY}

With these limitations and potential future research directions in mind, we hope our simple tenets meet the Lewinian standard of comprising a good, practical theory (Lewin, 1951). However, much of the theory's ultimate utility will be clarified by the extent to which educators can use it to inform their practice, researchers can use it to make theoretical predictions, and educators and scholars alike can use it to guide the development of interventions. 
Practicality for educators. We imagine that our theory could help practicing educators in three related ways: (a) by sharpening educators' ability to diagnose when biases might negatively impact their own social interactions, (b) by helping them identify and leverage teachable moments with their students, and (c) through proactively structuring learning experiences that allow students to practice mitigating bias in their person perception attempts.

Given how pressed for time teachers and school leaders are, it seems unrealistic that they will dedicate the hours to develop a working understanding for each of the biases that affect so many of the social interactions around their schools. Furthermore, the act of teaching presents an exceptionally challenging perspective taking task in that teachers must simultaneously convey content and monitor classroom behavior, while tracking the comprehension of dozens of individual students. By distilling the myriad of person perception biases down to two core motives, our theory provides an essential understanding in a framework simple enough for educators to employ during teaching. With this theory in the back of their minds, teachers can evaluate when their biases affect their interactions with students (or with one another). For instance, if a teacher notices an interaction with a particular student starting to sour, he can easily assess the likelihood that his biases might be contributing to the problem. Specifically, he can assess whether he is feeling defensive (which might imply a threat to the ego), is under time pressure or cognitive load (which might imply a cognitive efficiency bias), or a combination of the two. In short, a working knowledge of our proposed meta-biases could help educators selfdiagnose what role their own biases might be playing in different social interactions.

In addition, the theory may help educators identify and leverage teachable moments as they monitor social interactions between students. When students' interactions deteriorate into unproductive conflicts, teachers can assess whether, and in what way, particular biased perceptions might be contributing to the discord. Because biased perceptions from one party may engender reciprocal biased perceptions, teachers or counselors may have valuable opportunities to help students practice social perspective taking during these conflicts. With a working knowledge of the underlying motives that may be derailing the accuracy of students' perceptions, educators are much better positioned to assess the opportunity. For those instances that represent quality learning opportunities, teachers can guide a discussion in which students listen to, explain, and recalibrate their respective perspectives. For students, opportunities to 
practice and get feedback on their perspective taking attempts may be rare relative to the number of daily attempts they make (Gehlbach, 2017); chances to learn how their biases are impacting their perceptions are presumably even more unusual. Thus, endowing educators with more capacity to take advantage of these teachable moments seems particularly important.

Finally, more clarity on how biased perceptions can derail our person perception efforts can help educators teach more systematically about the role of bias in how we understand each other. Our theory allows educators to more easily extract lessons about the role of bias in social perspective taking from existing curricula. For example, numerous history lessons bring to light the most severe consequences of in-group/out-group bias from conflicts between Hutus and Tutsis, Arabs and Israelis, to the Nazi program of genocide in World War II. Staples of many literature courses provide excellent discussion points for naïve realism (Catch-22), or stereotyping (novels by Richard Wright, Toni Morrison, Harper Lee, etc.). Many curricula explicitly work on social emotional learning (e.g., Second Step, Facing History and Ourselves) or broader philosophical approaches to schooling that address many of these same outcomes (e.g., EL Education). With more clarity on how biases interact with our person perception attempts, educators will be better positioned to assess what their students need to work on and which curricula might provide optimal matches. Naturally, this understanding of bias could also prove valuable for teachers creating their own lessons or school leaders attempting to shift school norms.

Utility for scholars. We hope interested researchers might gain different benefits from the theory. First, the theory can help generate hypotheses to further scientific understanding of the interplay between bias and person perception. Future studies might test the extent to which rewarding accurate social perception minimizes bias; assess the conditions under which each meta-bias tends to become strongest relative to the other motives; explore how the interaction of multiple biases - for instance, our previous example of confirmation bias - may affect person perception differently than single biases; and so forth.

Second, because the theory distills and synthesizes multiple biases into two meta-biases, it may facilitate more field research, thereby facilitating our understanding of how well past laboratory studies generalize to real-world environments. In other words, when multiple situational forces bear down on students, our more synthetic theory may be better positioned to 
predict the net impact in real-world situations than more discrete theories about specific biases. For instance, how much do students still see themselves as above average in classroom contexts where the relative performance of students is made public, teacher expectancy effects are salient, and in-groups and out-groups are prominent?

Third, our theory may help advance understanding of biases through comparisons with other theories. For instance, we argued that cognitive consistency enhances positive perceptions of ourselves because we see ourselves as stable, competent, and morally good. Designing studies to place these two propositions in tension could further our theoretical understanding of the motives underlying some of our biases. For example, tests of cognitive consistency could be varied so that some tests are self-enhancing while others are not. If cognitive consistency is a core motive (Gawronski, 2012) people should try to stay just as consistent regardless of whether doing so is self-enhancing. We predict that the drive for cognitive consistency will be significantly stronger when one's sense of self is implicated.

Development of Interventions. The theory will be most useful to scholars and educators to the extent that it facilitates the development of interventions to reduce biased person perception. For instance, we might expect that an intervention to encourage students to put forth more cognitive effort over a longer time as they perceive classmates might reduce anchoring and adjusting, stereotyping, fundamental attribution error, and availability biases (assuming all were relevant) on person perception tasks. We might also predict that interventions that require teachers to articulate multiple hypotheses for why a particularly baffling student is behaving in a certain way might help to counteract confirmation bias. Our theory would predict that this intervention might also coincide with a drop in teachers' confidence given that we have theorized that confirmation bias primarily addresses the self-enhancement motive. Thus, in addition to guiding educators' in-the-moment understanding of their classrooms and scholars' theoretical understanding, we especially hope that this theory generates ideas for interventions. As these interventions are tested, the results should inform classroom practices and theory alike. Most of all, effective interventions should mitigate the damage that biased social perspective taking attempts can do to interpersonal relationships. 
As the world becomes more global and conflicts require more cross-cultural collaboration, the need for more accurate social perspective taking grows more pressing. Increasingly diverse schools in many parts of the world provide a parallel, local need for reducing bias in person perception. However, diverse schools also provide excellent environments for helping students develop their social perspective taking capacities. We hope our theory of how the two core motives underlying the biases in our person perception attempts provides some good, practical guidance for educators helping develop these capacities in our youth. 


\section{References}

Ames, D. R. (2004a). Inside the mind-reader's toolkit: Projection and stereotyping in mental state inference. Journal of Personality and Social Psychology, 87(3), 340-353.

Ames, D. R. (2004b). Strategies for social inference: A similarity contingency model of projection and stereotyping in attribute prevalence estimates. Journal of Personality and Social Psychology, 87(5), 573-585.

Aronson, E. (1992). The return of the repressed: Dissonance theory makes a comeback. Psychological Inquiry, 3(4), 303-311.

Batson, C. D., Early, S., \& Salvarani, G. (1997). Perspective taking: Imagining how another feels versus imagining how you would feel. Personality and Social Psychology Bulletin, 23(7), 751-758.

Bissonnette, V. L., Rusbult, C. E., \& Kilpatrick, S. D. (1997). Empathic accuracy and marital conflict resolution. In W. J. Ickes (Ed.), Empathic accuracy (pp. 251-281). New York, NY, US: Guilford Press.

Brophy, J. E. (1983). Research on the self-fulfilling prophecy and teacher expectations. Journal of Educational Psychology, 75(5), 631-661.

Cacioppo, J. T., \& Petty, R. E. (1982). The need for cognition. Journal of Personality and Social Psychology, 42(1), 116-131.

Cohen, E. G. (1994). Designing groupwork: Strategies for the heterogeneous classroom (2nd ed.). New York: Teachers College Columbia University.

Corno, L., Cronbach, L. J., Kupermintz, H., Lohman, D. F., Mandinach, E. B., Porteus, A. W., \& Talbert, J. E. (2002). Remaking the concept of aptitude: Extending the legacy of Richard E. Snow. Mahwah, NJ: Lawrence Erlbaum Associates.

Crick, N. R., \& Dodge, K. A. (1996). Social information-processing mechanisms in reactive and proactive aggression. Child Development, 67(3), 993-1002. doi:10.2307/1131875

Davis, M. H., Conklin, L., Smith, A., \& Luce, C. (1996). Effect of perspective taking on the cognitive representation of persons: A merging of self and other. Journal of Personality \& Social Psychology, 70(4), 713-726.

Davis, M. H., \& Kraus, L. A. (1997). Personality and empathic accuracy. In W. J. Ickes (Ed.), Empathic accuracy (pp. 144-168). New York: The Guilford Press.

Devine, P. (1995). Prejudice and out-group perception. In A. Tesser (Ed.), Advanced social psychology (pp. 466524). New York: McGraw-Hill.

Dunning, D. (1999). A newer look: Motivated social cognition and the schematic representation of social concepts. Psychological Inquiry, 10(1), 1.

Dunning, D., Griffin, D. W., Milojkovic, J. D., \& Ross, L. (1990). The overconfidence effect in social prediction. Journal of Personality and Social Psychology, 58(4), 568-581.

Egalite, A. J., \& Kisida, B. (2017). The effects of teacher match on students' academic perceptions and attitudes. Educational Evaluation and Policy Analysis, 0162373717714056. doi:10.3102/0162373717714056

Ekman, P., O'Sullivan, M., \& Frank, M. G. (1999). A few can catch a liar. Psychological Science, 10(3), $263-266$. 
Epley, N., \& Gilovich, T. (2006). The anchoring-and-adjustment heuristic: Why the adjustments are insufficient. Psychological Science, 17(4), 311-318.

Epley, N., Keysar, B., Van Boven, L., \& Gilovich, T. (2004). Perspective taking as egocentric anchoring and adjustment. Journal of Personality and Social Psychology, 87(3), 327-339.

Eyal, T., Steffel, M., \& Epley, N. (2018). Perspective mistaking: Accurately understanding the mind of another requires getting perspective, not taking perspective. Journal of Personality and Social Psychology, 114(4), 547-571.

Fiske, S. T. (1995). Social cognition. In A. Tesser (Ed.), Advanced social psychology (pp. 145-194). New York: McGraw-Hill.

Friedman, T. L. (2006). The world is flat: A brief history of the twenty-first century (1st updated and expanded ed.). New York: Farrar Straus and Giroux.

Galinsky, A. D., Ku, G., \& Wang, C. S. (2005). Perspective-taking and self other overlap: Fostering social bonds and facilitating social coordination. Group Processes \& Intergroup Relations, 8(2), 109-124.

Galinsky, A. D., \& Moskowitz, G. B. (2000). Perspective-taking: Decreasing stereotype expression, stereotype accessibility, and in-group favoritism. Journal of Personality and Social Psychology, 78(4), 708-724. doi:10.1037//0022-3514.78.4.708

Gawronski, B. (2012). Back to the future of dissonance theory: Cognitive consistency as a core motive. Social Cognition, 30(6), 652-668. doi:http://dx.doi.org/10.1521/soco.2012.30.6.652

Gehlbach, H. (2004). A new perspective on perspective taking: A multidimensional approach to conceptualizing an aptitude. Educational Psychology Review, 16(3), 207-234. doi:10.1023/b:edpr.0000034021.12899.11

Gehlbach, H. (2011). Making social studies social: Engaging students through different forms of social perspective taking. Theory into Practice, 50(4), 311-318. doi:10.1080/00405841.2011.607394

Gehlbach, H. (2017). Learning to walk in another's shoes. Phi Delta Kappan, 98(6), 8-12.

Gehlbach, H., \& Brinkworth, M. E. (2008). Motivated thinkers and the mistakes they make: The goals underlying social cognitions and their consequences for achievement. In M. L. Maehr, S. Karabenick, \& T. Urdan (Eds.), Advances in motivation and achievement: Social psychological perspectives. (Vol. 15, pp. 119-144). Bingley, UK: Emerald.

Gehlbach, H., \& Brinkworth, M. E. (2012). The social perspective taking process: Strategies and sources of evidence in taking another's perspective. Teachers College Record, 114(1), 29.

Gehlbach, H., Brinkworth, M. E., \& Harris, A. D. (2012). Changes in teacher-student relationships. British Journal of Educational Psychology, 82, 690-704. doi:10.1111/j.2044-8279.2011.02058.x

Gehlbach, H., Brinkworth, M. E., \& Wang, M.-T. (2012). The social perspective taking process: What motivates individuals to take another's perspective? Teachers College Record, 114(1), 29.

Gehlbach, H., Marietta, G., King, A., Karutz, C., Bailenson, J. N., \& Dede, C. (2015). Many ways to walk a mile in another's moccasins: Type of social perspective taking and its effect on negotiation outcomes. Computers in Human Behavior, 52, 523-532. doi:10.1016/j.chb.2014.12.035 
Gilbert, D. T. (1995). Attribution and interpersonal perception. In A. Tesser (Ed.), Advanced social psychology (pp. 98-147). New York: McGraw-Hill.

Gilbert, D. T., \& Wilson, T. D. (2007). Prospection: Experiencing the future. Science, 317(5843), 1351-1354. doi:10.1126/science.1144161

Gilovich, T., Medvec, V. H., \& Savitsky, K. (2000). The spotlight effect in social judgment: An egocentric bias in estimates of the salience of one's own actions and appearance. Journal of Personality and Social Psychology, 78(2), 211-222.

Gilovich, T., \& Ross, L. (2015). The wisest one in the room: How you can benefit from social psychology's most powerful insights (First Free Press hardcover edition. ed.). New York: Free Press.

Gleason, K. A., Jensen-Campbell, L. A., \& Ickes, W. (2009). The role of empathic accuracy in adolescents' peer relations and adjustment. Personality and Social Psychology Bulletin, 35(8), 997-1011.

Goethals, G. R., Messick, D. M., \& Allison, S. T. (1991). The uniqueness bias: Studies of constructive social comparison. In J. Suls \& T. A. Wills (Eds.), Social comparison: Contemporary theory and research (pp. 149176, Chapter xv, 431 Pages): Lawrence Erlbaum Associates, Inc, Hillsdale, NJ.

Gross, J. J. (1998). The emerging field of emotion regulation: An integrative review. Review of General Psychology, 2(3), 271-299.

Hewstone, M., Rubin, M., \& Willis, H. (2002). Intergroup bias. Annual Review of Psychology, 53(1), 575-604.

Ickes, W. J. (Ed.) (1997). Empathic accuracy. New York: The Guilford Press.

Johnson, D. W., \& Johnson, R. T. (2009). An educational psychology success story: Social interdependence theory and cooperative learning. Educational Researcher, 38(5), 365-379. doi:10.3102/0013189X09339057

Jones, E. E., \& Nisbett, R. E. (1971). The actor and the observer: Divergent perceptions of the causes of behavior. In E. E. Jones, D. E. Kanouse, H. H. Kelly, R. E. Nisbett, S. Valins, \& B. Weiner (Eds.), Attribution: Perceiving the causes of behavior. (pp. 79-94). Morristown, NJ: General Learning Press.

Jussim, L., Crawford, J. T., \& Rubinstein, R. S. (2015). Stereotype (in)accuracy in perceptions of groups and individuals. Current Directions in Psychological Science, 24(6), 490-497. doi:http://dx.doi.org/10.1177/0963721415605257

Jussim, L., \& Eccles, J. S. (1992). Teacher expectations: II. Construction and reflection of student achievement. Journal of Personality and Social Psychology, 63(6), 947-961.

Kahneman, D. (2011). Thinking, fast and slow. New York, NY US: Farrar, Straus and Giroux.

Kruger, J. (1999). Lake Wobegon be gone! The 'below-average effect' and the egocentric nature of comparative ability judgments. Journal of Personality and Social Psychology, 77(2), 221-232.

Kruger, J., \& Dunning, D. (1999). Unskilled and unaware of it: How difficulties in recognizing one's own incompetence lead to inflated self-assessments. Journal of Personality and Social Psychology, 77(6), 11211134.

Kunda, Z. (1990). The case for motivated reasoning. Psychological Bulletin, 108(3), 480-498. 
Kunda, Z., \& Sinclair, L. (1999). Motivated reasoning with stereotypes: Activation, application, and inhibition. Psychological Inquiry, 10(1), 12-22. doi:http://dx.doi.org/10.1207/s15327965pli1001 2

Lewin, K. (1951). Field theory in social science: selected theoretical papers (Edited by Dorwin Cartwright.): Harpers, Oxford.

Liberman, V., Minson, J. A., Bryan, C. J., \& Ross, L. (2011). Naïve realism and capturing the "wisdom of dyads". Journal of Experimental Social Psychology. doi:10.1016/j.jesp.2011.10.016

Lieberman, M. D. (2013). Social: Why our brains are wired to connect (First ed.). New York: Crown Publishers.

Lord, C. G., Lepper, M. R., \& Preston, E. (1984). Considering the opposite: A corrective strategy for social judgment. Journal of Personality and Social Psychology, 47(6), 1231-1243.

Lotan, R. A. (1997). Complex instruction: An overview. In E. G. Cohen \& R. A. Lotan (Eds.), Working for equity in heterogeneous classrooms: Sociological theory in practice (pp. 15-27). New York: Teachers College Press.

Montoya, R. M., Horton, R. S., \& Kirchner, J. (2008). Is actual similarity necessary for attraction? A meta-analysis of actual and perceived similarity. Journal of Social and Personal Relationships, 25(6), 889-922. doi:10.1177/0265407508096700

Myers, D. G. (2015). Exploring social psychology (7th ed.). New York: McGraw-Hill.

National Center for Educational Statistics. (2012). Total number of public school teachers and percentage distribution of school teachers, by race/ethnicity and state: 2011-12. Retrieved from https://nces.ed.gov/surveys/sass/tables/sass1112 2013314 t1s 001.asp

Nickerson, R. S. (1998). Confirmation bias: A ubiquitous phenomenon in many guises. Review of General Psychology, 2(2), 175-220. doi:http://dx.doi.org/10.1037/1089-2680.2.2.175

Nisbett, R. E., Peng, K., Choi, I., \& Norenzayan, A. (2001). Culture and systems of thought: Holistic versus analytic cognition. Psychological Review, 108(2), 291-310.

Pelham, B. W., Carvallo, M., \& Jones, J. T. (2005). Implicit egotism. Current Directions in Psychological Science, 14(2), 106-110. doi:10.1111/j.0963-7214.2005.00344.x

Pelham, B. W., Mirenberg, M. C., \& Jones, J. T. (2002). Why Susie sells seashells by the seashore: Implicit egotism and major life decisions. Journal of Personality and Social Psychology, 82(4), 469-487. doi:10.1037/00223514.82.4.469

Pronin, E., Gilovich, T., \& Ross, L. (2004). Objectivity in the eye of the beholder: Divergent perceptions of bias in self versus others. Psychological Review, 111(3), 781-799.

Pronin, E., Kruger, J., Savtisky, K., \& Ross, L. (2001). You don't know me, but I know you: The illusion of asymmetric insight. Journal of Personality and Social Psychology, 81(4), 639-656.

Robinson, R. J., Keltner, D., Ward, A., \& Ross, L. (1995). Actual versus assumed differences in construal: 'Naive realism' in intergroup perception and conflict. Journal of Personality and Social Psychology, 68(3), 404417.

Rosenthal, R. (1991). Teacher expectancy effects: A brief update 25 years after the pygmalion experiment. Journal of Research in Education, 1(1), 3-12. 
Rosenthal, R., \& Jacobson, L. (1968). Pygmalion in the classroom; teacher expectation and pupils' intellectual development. New York: Holt Rinehart and Winston.

Ross, L. (1981). The "intuitive scientist" formulation and its developmental implications. In J. H. Flavell \& L. Ross (Eds.), Social cognitive development: Frontiers and possible futures (pp. 1-42). Cambridge: Cambridge University Press.

Ross, L., Amabile, T. M., \& Steinmetz, J. L. (1977). Social roles, social control, and biases in social-perception processes. Journal of Personality and Social Psychology, 35(7), 485-494.

Ross, L., Greene, D., \& House, P. (1977). The false consensus effect: An egocentric bias in social perception and attribution processes. Journal of Experimental Social Psychology, 13(3), 279-301.

Ross, L., \& Ward, A. (1996). Naive realism in everyday life: Implications for social conflict and misunderstanding. In E. S. Reed \& E. Turiel (Eds.), Values and knowledge (pp. 103-135). Mahwah: Lawrence Erlbaum Associates Inc.

Simpson, J. A., Ickes, W. J., \& Blackstone, T. (1995). When the head protects the heart: Empathic accuracy in dating relationships. Journal of Personality and Social Psychology, 69(4), 629-641.

Snow, R. E. (1996). Aptitude development and education. Psychology, Public Policy, and Law, 2(3/4), 536-560.

Snyder, M., Tanke, E. D., \& Berscheid, E. (1977). Social perception and interpersonal behavior: On the self-fulfilling nature of social stereotypes. Journal of Personality and Social Psychology, 35(9), 656-666.

Steele, C. M. (1988). The psychology of self-affirmation: Sustaining the integrity of the self. In L. Berkowitz (Ed.), Advances in experimental social psychology, Vol. 21: Social psychological studies of the self: Perspectives and programs (pp. 261-302, Chapter x, 361 Pages): Academic Press, San Diego, CA.

Swann, W. B. (1997). The trouble with change: Self-verification and allegiance to the self. Psychological Science, 8(3), 177-180. doi:http://dx.doi.org/10.1111/j.1467-9280.1997.tb00407.x

Swann, W. B., \& Schroeder, D. G. (1995). The search for beauty and truth: A framework for understanding reactions to evaluations. Personality and Social Psychology Bulletin, 21(12), 1307-1318. doi:http://dx.doi.org/10.1177/01461672952112008

Swann, W. B., Stein-Seroussi, A., \& Giesler, R. B. (1992). Why people self-verify. Journal of Personality and Social Psychology, 62(3), 392-401. doi:http://dx.doi.org/10.1037/0022-3514.62.3.392

Tamir, D. I., \& Mitchell, J. P. (2013). Anchoring and adjustment during social inferences. Journal of Experimental Psychology: General, 142(1), 151-162. doi:10.1037/a0028232

Tversky, A., \& Kahneman, D. (1974). Judgment under uncertainty: Heuristics and biases. Science, 185(4157), 11241131.

Weiner, B. (1994). Integrating social and personal theories of achievement striving. Review of Educational Research, 64(4), 557-573.

Zaki, J. (2014). Empathy: A motivated account. Psychological Bulletin, 140(6), 1608-1647. 